\title{
Between-day reliability of pedal forces for cyclists during an incremental cycling test to exhaustion
}

\author{
Rodrigo R. Bini ${ }^{\mathrm{a}, \mathrm{b}, *}$ and Patria A. Hume ${ }^{\mathrm{a}}$ \\ a Sport Performance Research Institute New Zealand, Auckland University of Technology, Auckland, New Zealand \\ ${ }^{\mathrm{b}}$ Capes Foundation, Ministry of Education of Brazil, Brasilia, Brasil
}

Received 3 July 2012

Accepted 5 August 2012

\begin{abstract}
.
BACKGROUND: Reliability of pedal forces during cycling specific tests needs to be established if pedal forces are to be used in longitudinal studies evaluating performance improvements.

METHOD: We assessed the reliability of pedal force measures during two incremental cycling tests to exhaustion separated by two to seven days. The number of competitive cyclists completing each workload increment varied $(n=10$ for $100 \mathrm{~W}$ to $250 \mathrm{~W} ; n=8$ for $300 \mathrm{~W} ; n=6$ for $350 \mathrm{~W}$ ). Pedal forces were measured via strain gauge instrumented pedals and pedal-to-crank angles via angular potentiometers attached to the pedal spindles. Mean and standard deviations, typical error of measurement percentage (TE\%) and effect sizes (ES) between days across workloads for oxygen uptake $\left(\mathrm{VO}_{2}\right)$, peak normal force $(\mathrm{PNF})$, peak anterior-posterior force (PAPF), average total force on the pedal (ATF) and index of effectiveness percentage (IE) for right and left pedals were calculated.

RESULTS: Averages across all workloads showed high reliability and trivial differences between two to seven days of testing for all variables $\left(\mathrm{TE} \%, \mathrm{ICC}, \mathrm{ES} ; \mathrm{VO}_{2}=4 \%, 0.94,0.1\right.$ PNFright $=6 \%, 0.98,0.1 ;$ PNFleft $=12 \%, 0.98,0.1 ;$ PAPFright $=13 \%$, $0.95,0.2 ;$ PAPFleft $=14 \%, 0.96,0.1 ;$ ATFright $=5 \%, 0.98,0.1 ;$ ATFleft $=11 \%, 0.97,0.1 ;$ IEright $=10 \%, 0.94,0.2 ;$ IEleft $=$ $14 \%, 0.91,0.1)$.

CONCLUSION: Pedal force measures during incremental cycling tests to exhaustion can be used to assess changes in performance given the high reliability reported in our study.
\end{abstract}

Keywords: Pedalling technique, kinetics, biomechanics, performance

\section{Introduction}

Cycling laboratory-based assessment has been extensively used to assess variables that can predict athletic performance [1]. Physiological $\left(\mathrm{VO}_{2}\right.$ and heart rate) and biomechanical variables (power output) have

${ }^{*}$ Corresponding author: Rodrigo R. Bini, Sport Performance Research Institute New Zealand, School of Sport and Recreation, Auckland University of Technology, Private Bag 92006, Auckland, New Zealand. Tel.: +6499219999 ext 7295; Fax: +64 9921 9960; E-mail: bini.rodrigo@gmail.com. been amongst the main variables used to predict cycling performance and to assess training effects [2]. Pedal forces have been also measured during laboratory tests using varying protocols [3-5]. There has been an increasing interest in monitoring training effects on the effectiveness of pedal forces (ratio between force driving the crank by the total force on the pedal) [6].

Detecting changes in predictive measures such as pedal forces depends, at least in part, on the inherent variation associated with these measures and the precision with which they can be measured. Reliability 
refers to whether a specific measurement procedure results in consistent outcomes during repeated measures of the same variable [7]. Highly sensitive sports science measurements are characterised by little variation in consecutive measures of performance [8]. The advantage of small test-retest variability within and between sessions is that any change in the athlete's performance can more confidently be attributed to their recent training history, and not random fluctuations [8]. The change in performance due to the intervention has to be greater than the normal within- or between session variation before coaches can conclude that the intervention has had a meaningful impact on the athlete's performance [9].

The reliability of pedal forces during cycling specific tests needs to be established if they are to be used in longitudinal studies evaluating performance improvements. However, between-day reliability of pedal force measurements has not yet been presented. Reliability of cycling performance during laboratory based tests has been shown for peak power output during $30 \mathrm{~s}$ sprint performance (1.2-1.6\%) [10], 40-km time trial performance (3.5-4.5\%) [11] and cycling efficiency $(\sim 0.6 \%)$ [12]. Hug et al. [13] reported that variability in the effectiveness of pedal forces within a single session was 7.7-12.4\% when competitive cyclists were assessed at workloads of $150 \mathrm{~W}$ and $250 \mathrm{~W}$. However, no published study was found comparing effectiveness of pedal forces and other pedal force variables (e.g. total pedal force) in sessions conducted on separate days. This information is important for assessing the smallest worthwhile effect of training interventions for pedal force variables.

Incremental cycling exercise to exhaustion is a widely accepted cycling performance test which enables the measurement of physiological variables such as oxygen uptake [14] and ventilatory thresholds [15] during maximal effort. Recently, biomechanical variables such as muscle activity [16] and joint kinetics and kinematics [3] have been measured during incremental tests to exhaustion. The rationale for linking biomechanical and physiological variables is that more realistic comparisons can be conducted between cyclists of different performance levels, instead of the definition of a set workload level. During the incremental test, workload is controlled and gradually increased until exhaustion and cyclists are instructed to control pedalling cadence using visual feedback [17]. Therefore, the incremental test is a well-controlled test providing the possibility to compare results across subjects of varying performance levels by percentage of maximal performance or by percentage of ventilatory threshold. The incremental test is a suitable test to assess pedal forces when workload is increased in a step profile, which secures a minimum time at each consistent workload.

Therefore, the aim of our study was to assess the reliability of pedal force measures during two incremental cycling tests to exhaustion separated by two to seven days.

\section{Methods}

A quantitative repeated measures experimental design was used to collect data. Ten cyclists with competitive experience in cycling and triathlon were invited to participate in the study. Cyclists' (mean and standard deviation was $34 \pm 8$ years, $72 \pm 13 \mathrm{~kg}, 177 \pm 12 \mathrm{~cm}$, $59.6 \pm 7.4 \mathrm{ml} \cdot \mathrm{kg}^{-1} \cdot \mathrm{min}^{-1}$ maximal oxygen uptake, $372 \pm 80 \mathrm{~W}$ peak power output, $5.2 \pm 0.7 \mathrm{~W} \cdot \mathrm{kg}^{-1}$ peak power per body mass) signed an informed consent form in agreement with the committee of ethics in research of the institution where this study was conducted. No cyclist had an injury that would impact on test performance at the time of data collection.

Pedal force components (normal and anteriorposterior) were calibrated using the regression between three static load points $(0 \mathrm{~kg}, 5 \mathrm{~kg}$ and $10 \mathrm{~kg}$ ) applied to the pedals and voltage output when $R^{2}$ was greater than 0.99. Mechanical coupling between anterior-posterior and normal loads were corrected using a gain matrix [4]. Angular potentiometers attached to the pedal spindles were calibrated using a manual goniometer set at four angles $\left(0^{\circ}, 90^{\circ}, 180^{\circ}\right.$ and $\left.270^{\circ}\right)$ to compute the relationship between voltage output and the measured angle. The calibration factors were defined when mean differences in voltage were $\leqslant 1 \%$.

Body mass and height were measured according to ISAK protocols [18]. Cyclists/triathletes completed the Waterloo inventory to allow the determination of lower limb dominance [19]. Cyclists/triathletes' bicycle saddle height and horizontal position were measured to set-up the stationary cycle ergometer (Velotron, Racemate, Inc). Cyclists/triathletes performed an incremental cycling exercise on the cycle ergometer with three minutes of warm-up at $100 \mathrm{~W}$ and pedaling cadence visually controlled at $90 \pm 2 \mathrm{rpm}$. Workload was then increased to $150 \mathrm{~W}$ and remained increasing in a step profile of $25 \mathrm{~W} / \mathrm{min}$ until cyclists' exhaustion [14]. A script was configured in the Velotron CS2008 software (Velotron, Racemate, Inc, Seattle, USA) for automatic 
control of the constant workload mode with cycle ergometer resistance constantly changing to balance for fluctuations in pedalling cadence. Gas exchanges were continuously sampled from a mixing chamber where samples were drawn into the oxygen and carbon dioxide analyzers for continuous measurement using a metabolic cart (TrueOne 2400, Parvo Medics, Salt Lake City, UT, USA). Analyzers for oxygen and carbon dioxide were calibrated according to manufacturer recommendations. Maximal aerobic workload and maximal oxygen uptake were defined as the highest workload measured during the test and as the highest oxygen uptake value computed over a $15 \mathrm{~s}$ average of the data, respectively. After two to seven days from the first testing session, cyclists/triathletes returned to the laboratory at the approximate same time of the day to perform the incremental test following the same procedures. Due to the training schedules of the competitive cyclists/triathletes a consistent two day test-retest period was not always possible. The second session of testing was conducted where there was similar training load prior to the first testing session to try to ensure that the pre-test conditions were similar in terms of physical rest and preparedness for the testing sessions. Cyclists/triathletes were instructed to refrain from high intensity or long duration training on the day before each evaluation session.

Normal and anterior-posterior forces were measured using a pair of strain gauge instrumented pedals [20], with pedal-to-crank angle measured using angular potentiometers attached to the pedal spindle. Pedal force data passed through an amplifier (Applied Measurements, Australia) and, along with potentiometers and reed switch signals were recorded using an analogue to digital board PCI-MIO-16XE-50 (National Instruments, USA) at $600 \mathrm{~Hz}$ per channel using a custom made script in Matlab (Mathworks Inc, MA). Analogue data were acquired between the $20^{\text {th }}$ and the $40^{\text {th }} \mathrm{s}$ of each step of $50 \mathrm{~W}$ (i.e. $100 \mathrm{~W}, 150 \mathrm{~W}, 200 \mathrm{~W}$, $250 \mathrm{~W}$, etc.).

\subsection{Data analyses}

Pedal-to-crank angle (see Fig. 1) measured by the potentiometers were converted into sine and cosine to compute tangential and radial forces on the cranks. Low pass zero lag Butterworth digital filter with cut of frequency of $10 \mathrm{~Hz}$ was applied to the sine and cosine data from potentiometers to attenuate signal noise from gap in potentiometer voltage readings [21].

A reed switch attached to the bicycle frame detected the position of the crank in relation to the pedal revolu-

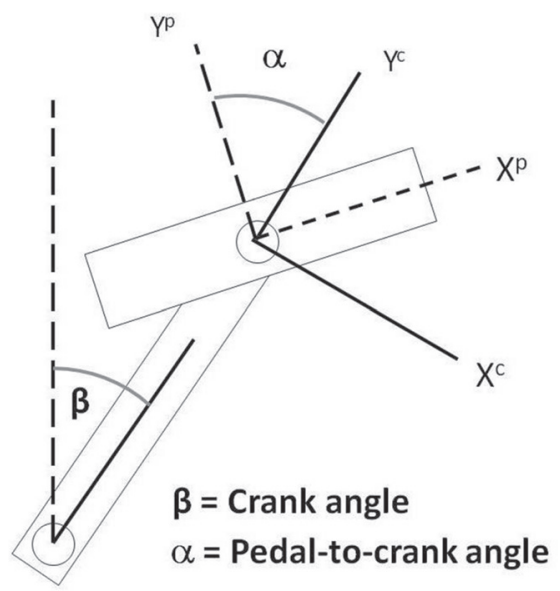

Fig. 1. Definition of crank angle and pedal-to-crank angle for vertical and horizontal axis of the crank $\left(\mathrm{X}^{\mathrm{C}}\right.$ and $\left.\mathrm{Y}^{\mathrm{C}}\right)$ and the pedal $\left(\mathrm{X}^{\mathrm{P}}\right.$ and $\left.\mathrm{Y}^{\mathrm{P}}\right)$. Normal and anterior-posterior pedal forces were defined analogue to $\mathrm{X}^{\mathrm{p}}$ and $\mathrm{Y}^{\mathrm{p}}$, respectively.

tion and enabled to separate pedal force data into every crank revolution. Peak normal and anterior-posterior force on the pedals were computed along with the average total force applied on the sagittal plane of the pedal surface. Pedal force effectiveness was assessed by the index of effectiveness computed as the ratio between the angular impulse of the tangential force on the crank and the linear impulse of the total force applied on the pedal [22]. All force variables were averaged for each subject across five revolutions of the crank for each stage of the incremental test. Oxygen uptake was averaged for each stage of the incremental test.

\subsection{Statistical analyses}

Errors of calibration of normal and anterior-posterior components and potentiometers of the pedals were computed as average percentage differences in voltage due to calibration load (or angle for potentiometer) in relation to the output voltage. As an example, for the normal force of the right pedal, the difference in voltage from $0 \mathrm{~kg}$ to $5 \mathrm{~kg}$ was $0.1547 \mathrm{~V}$ and the difference in voltage from $5 \mathrm{~kg}$ to $10 \mathrm{~kg}$ was $0.1544 \mathrm{~V}$, resulting in $0.19 \%$ difference in voltage due to load application. Variation in pedalling cadence was computed by percentage differences across five crank revolutions.

Peak normal and anterior-posterior pedal forces, average total force applied on the pedal, index of effectiveness and oxygen uptake were compared between both days of evaluation session. All variables were analyzed for the $100 \mathrm{~W}, 150 \mathrm{~W}, 200 \mathrm{~W}, 250 \mathrm{~W}, 300 \mathrm{~W}$ and $350 \mathrm{~W}$ stages of the incremental test. Normality 
Table 1

Mean and standard deviations, typical error of measurement $(\%)$ and effect sizes between days across different workload levels for oxygen uptake $\left(\mathrm{VO}_{2}\right)$, peak normal force (NF), peak anterior-posterior force (APF), average total force on the pedal and index of effectiveness (IE) for averages of right and left pedals. The number of cyclists completing each stage varied ( $n=10$ for $100 \mathrm{~W}$ to $250 \mathrm{~W} ; n=8$ for $300 \mathrm{~W} ; n=6$ for $350 \mathrm{~W}$ ). Abbreviations used are for effect sizes of trivial (T), small (S), moderate (M) and large (L), typical error (TE) and effect sizes (ES)

\begin{tabular}{|c|c|c|c|c|c|c|c|}
\hline Variables & $\begin{array}{c}100 \mathrm{~W} \\
(n=10)\end{array}$ & $\begin{array}{c}150 \mathrm{~W} \\
(n=10)\end{array}$ & $\begin{array}{c}200 \mathrm{~W} \\
(n=10)\end{array}$ & $\begin{array}{c}250 \mathrm{~W} \\
(n=8)\end{array}$ & $\begin{array}{c}300 \mathrm{~W} \\
(n=10)\end{array}$ & $\begin{array}{l}350 \mathrm{~W} \\
(n=6)\end{array}$ & $\begin{array}{c}\text { Average across all } \\
\text { stages typical error; ICC; } \\
\text { ES, magnitude inference }\end{array}$ \\
\hline \multicolumn{8}{|l|}{$\mathrm{VO}_{2}\left(\mathrm{ml} \cdot \mathrm{kg} \cdot \mathrm{min}^{-1}\right)$} \\
\hline Day 1 & $24 \pm 3$ & $26 \pm 3$ & $35 \pm 6$ & $42 \pm 5$ & $49 \pm 5$ & $54 \pm 7$ & - \\
\hline Day 2 & $23 \pm 3$ & $26 \pm 4$ & $35 \pm 5$ & $43 \pm 6$ & $49 \pm 5$ & $55 \pm 6$ & - \\
\hline $\begin{array}{l}\text { Day } 1 \text { vs. Day 2: TE; } \\
\text { ES, magnitude inference }\end{array}$ & $4 \% ; 0.1, \mathrm{~T}$ & $6 \% ; 0.1, \mathrm{~T}$ & $7 \% ; 0.1, \mathrm{~T}$ & $3 \% ; 0.2, \mathrm{~T}$ & $2 \% ; 0.1, \mathrm{~T}$ & $2 \% ; 0.1, \mathrm{~T}$ & $4 \% ; 0.94 ; 0.1, \mathrm{~T}$ \\
\hline \multicolumn{8}{|l|}{ Peak NF right $(\mathrm{N})$} \\
\hline Day 1 & $230 \pm 39$ & $264 \pm 37$ & $312 \pm 50$ & $359 \pm 52$ & $404 \pm 59$ & $464 \pm 63$ & - \\
\hline Day 2 & $228 \pm 41$ & $272 \pm 48$ & $312 \pm 52$ & $356 \pm 51$ & $408 \pm 59$ & $472 \pm 49$ & - \\
\hline $\begin{array}{l}\text { Day } 1 \text { vs. Day 2: TE; } \\
\text { ES, magnitude inference }\end{array}$ & $5 \% ; 0.1, \mathrm{~T}$ & $11 \% ; 0.2, \mathrm{~T}$ & $5 \% ; 0.1, \mathrm{~T}$ & $5 \% ; 0.1, \mathrm{~T}$ & $3 \% ; 0.1, \mathrm{~T}$ & $5 \% ; 0.1, \mathrm{~T}$ & $6 \% ; 0.98 ; 0.1, \mathrm{~T}$ \\
\hline \multicolumn{8}{|l|}{ Peak NF left $(N)$} \\
\hline Day 1 & $249 \pm 72$ & $292 \pm 84$ & $328 \pm 95$ & $353 \pm 110$ & $375 \pm 133$ & $404 \pm 138$ & \\
\hline Day 2 & $245 \pm 81$ & $292 \pm 95$ & $334 \pm 91$ & $349 \pm 142$ & $372 \pm 142$ & $397 \pm 114$ & \\
\hline $\begin{array}{l}\text { Day } 1 \text { vs. Day 2: TE; } \\
\text { ES, magnitude inference }\end{array}$ & $11 \% ; 0.1, \mathrm{~T}$ & $13 \% ; 0.1, \mathrm{~T}$ & $10 \% ; 0.1, \mathrm{~T}$ & $21 \% ; 0.1, \mathrm{~T}$ & $7 \% ; 0.1, \mathrm{~T}$ & $7 \% ; 0.1, \mathrm{~T}$ & $12 \% ; 0.98 ; 0.1, \mathrm{~T}$ \\
\hline \multicolumn{8}{|l|}{ Peak APF right $(\mathrm{N})$} \\
\hline Day 1 & $82 \pm 19$ & $96 \pm 23$ & $110 \pm 19$ & $107 \pm 22$ & $117 \pm 29$ & $109 \pm 30$ & \\
\hline Day 2 & $77 \pm 23$ & $99 \pm 21$ & $99 \pm 14$ & $106 \pm 20$ & $112 \pm 22$ & $103 \pm 31$ & \\
\hline $\begin{array}{l}\text { Day } 1 \text { vs. Day } 2: \text { TE; } \\
\text { ES, magnitude inference }\end{array}$ & $11 \% ; 0.2, \mathrm{~T}$ & $11 \% ; 0.1, \mathrm{~T}$ & $16 \% ; 0.6, \mathrm{M}$ & $8 \% ; 0.1, \mathrm{~T}$ & $17 \% ; 0.2, \mathrm{~T}$ & $13 \% ; 0.2, \mathrm{~T}$ & $13 \% ; 0.95 ; 0.2, \mathrm{~T}$ \\
\hline \multicolumn{8}{|l|}{ Peak APF left $(\mathrm{N})$} \\
\hline Day 1 & $65 \pm 18$ & $81 \pm 26$ & $97 \pm 20$ & $96 \pm 20$ & $98 \pm 15$ & $90 \pm 27$ & \\
\hline Day 2 & $80 \pm 33$ & $90 \pm 14$ & $90 \pm 17$ & $95 \pm 19$ & $95 \pm 18$ & $87 \pm 22$ & \\
\hline $\begin{array}{l}\text { Day } 1 \text { vs. Day } 2: \text { TE; } \\
\text { ES, magnitude inference }\end{array}$ & $13 \% ; 0.6, \mathrm{M}$ & $17 \% ; 0.4, S$ & $23 \% ; 0.3, \mathrm{~S}$ & $8 \% ; 0.1, \mathrm{~T}$ & $13 \% ; 0.2, \mathrm{~T}$ & $9 \% ; 0.1, \mathrm{~T}$ & $14 \% ; 0.96 ; 0.1, \mathrm{~T}$ \\
\hline \multicolumn{8}{|l|}{ Total force right $(\mathrm{N})$} \\
\hline Day 1 & $129 \pm 25$ & $138 \pm 26$ & $153 \pm 25$ & $164 \pm 25$ & $180 \pm 29$ & $201 \pm 29$ & \\
\hline Day 2 & $129 \pm 27$ & $141 \pm 28$ & $151 \pm 28$ & $161 \pm 28$ & $182 \pm 22$ & $194 \pm 25$ & \\
\hline $\begin{array}{l}\text { Day } 1 \text { vs. Day 2: TE; } \\
\text { ES, magnitude inference }\end{array}$ & $4 \% ; 0.1, \mathrm{~T}$ & $6 \% ; 0.1, \mathrm{~T}$ & $6 \% ; 0.1, \mathrm{~T}$ & $5 \% ; 0.1, \mathrm{~T}$ & $4 \% ; 0.1, \mathrm{~T}$ & $3 \% ; 0.3, \mathrm{~S}$ & $5 \% ; 0.98 ; 0.1, \mathrm{~T}$ \\
\hline \multicolumn{8}{|l|}{ Total force left $(\mathrm{N})$} \\
\hline Day 1 & $114 \pm 32$ & $127 \pm 32$ & $136 \pm 38$ & $145 \pm 52$ & $153 \pm 63$ & $162 \pm 59$ & \\
\hline Day 2 & $118 \pm 33$ & $130 \pm 41$ & $142 \pm 42$ & $146 \pm 57$ & $158 \pm 66$ & $165 \pm 53$ & \\
\hline $\begin{array}{l}\text { Day } 1 \text { vs. Day 2: TE; } \\
\text { ES, magnitude inference }\end{array}$ & $9 \% ; 0.1, \mathrm{~T}$ & $15 \% ; 0.1, \mathrm{~T}$ & $11 \% ; 0.1, \mathrm{~T}$ & $15 \% ; 0.1, \mathrm{~T}$ & $10 \% ; 0.1, \mathrm{~T}$ & $5 \% ; 0.1, \mathrm{~T}$ & $11 \% ; 0.97 ; 0.1, \mathrm{~T}$ \\
\hline \multicolumn{8}{|l|}{ IE right $(\%)$} \\
\hline Day 1 & $47 \pm 4$ & $54 \pm 5$ & $54 \pm 9$ & $61 \pm 4$ & $64 \pm 5$ & $66 \pm 4$ & \\
\hline Day 2 & $49 \pm 6$ & $55 \pm 8$ & $59 \pm 7$ & $61 \pm 11$ & $64 \pm 6$ & $67 \pm 7$ & \\
\hline $\begin{array}{l}\text { Day } 1 \text { vs. Day 2: TE; } \\
\text { ES, magnitude inference }\end{array}$ & $4 \% ; 0.4, \mathrm{~S}$ & $13 \% ; 0.2, \mathrm{~T}$ & $14 \% ; 0.6, \mathrm{M}$ & $17 \% ; 0.1, \mathrm{~T}$ & $6 \% ; 0.1, \mathrm{~T}$ & $5 \% ; 0.1, \mathrm{~T}$ & $10 \% ; 0.94 ; 0.2, \mathrm{~T}$ \\
\hline \multicolumn{8}{|l|}{ IE left $(\%)$} \\
\hline Day 1 & $36 \pm 9$ & $41 \pm 11$ & $42 \pm 8$ & $47 \pm 10$ & $49 \pm 13$ & $51 \pm 6$ & \\
\hline Day 2 & $36 \pm 7$ & $42 \pm 12$ & $43 \pm 14$ & $50 \pm 6$ & $46 \pm 15$ & $49 \pm 7$ & \\
\hline $\begin{array}{l}\text { Day } 1 \text { vs. Day } 2: \text { TE; } \\
\text { ES, magnitude inference }\end{array}$ & $10 \% ; 0.1, \mathrm{~T}$ & $16 \% ; 0.1, \mathrm{~T}$ & $15 \% ; 0.1, \mathrm{~T}$ & $12 \% ; 0.4, \mathrm{~S}$ & $22 \% ; 0.2, \mathrm{~T}$ & $10 \% ; 0.3, \mathrm{~S}$ & $14 \% ; 0.91 ; 0.1, \mathrm{~T}$ \\
\hline
\end{tabular}

of distribution and sphericity were evaluated via the Shapiro-Wilk and Mauchly tests respectively. For oxygen uptake, right normal force, and anterior-posterior right and left force, a logarithm transform was applied.

Typical error of measurements [23] and intraclass correlation coefficients (ICC) were calculated for all variables to ascertain reliability. SPSS for Windows 16.0 was employed for the analysis of ICC. Cohen's effect sizes (ES) were computed for the analysis of the magnitude of the differences and subsequently rated as trivial $(<0.25)$, small $(0.25-0.49)$, moderate $(0.5-1.0)$, and large $(>1.0)$ [24]. We chose large effect sizes for 
discussion of results to ascertain non-overlap between mean scores greater than 55\% [25].

In summary, mean and standard deviations, typical error of measurement percentage (TE\%) and effect sizes (ES) between days across workloads for oxygen uptake $\left(\mathrm{VO}_{2} \mathrm{ml} \cdot \mathrm{kg} \cdot \mathrm{min}^{-1}\right)$, peak normal force (PNF), peak anterior-posterior force (PAPF), average total force on the pedal (ATF) and index of effectiveness percentage (IE) for right and left pedals were calculated.

\section{Results}

Lower limb dominance assessed by the Waterloo inventory indicated that all ten cyclists reported right leg dominance for more than $80 \%$ of the questions of the inventory.

Errors from calibration procedures were $0.19 \%$ and $0.68 \%$ for the normal force, and $0.68 \%$ and $0.56 \%$ for anterior-posterior force for the right and left pedals, respectively. Error in pedal-to-crank angle of each potentiometer was $0.5 \%$. Mean variation in pedalling cadence between cyclists was $1 \%$ resulting in an estimated error from equipment of $\sim 1.37 \%$ and $\sim 1.74 \%$ for index of effectiveness of the right and left pedals, respectively.

Between-day differences ranged from trivial to moderate for most pedal force variables. There were trivial differences between days for oxygen uptake for all stages. Percentage differences measured by typical error ranged from $5 \%$ to $14 \%$ for pedal force variables and typical error was $4 \%$ for oxygen uptake with trivial differences assessed by effect sizes (see Table 1). Averages across all workloads showed high reliability and trivial differences between two to seven days of testing for all variables (TE\%, ICC, ES; $\mathrm{VO}_{2}=4 \%, 0.94,0.1$; PNFright $=6 \%, 0.98,0.1$; PNFleft $=12 \%, 0.98,0.1$; PAPFright $=13 \%, 0.95,0.2$; PAPFleft $=14 \%, 0.96$, 0.1 ; ATFright $=5 \%, 0.98,0.1$; ATFleft $=11 \%, 0.97$, 0.1 ; IEright $=10 \%, 0.94,0.2$; IEleft $=14 \%, 0.91,0.1$ ). Pedal force measures during incremental cycling tests to exhaustion can be used to assess changes in performance given the high reliability reported in our study.

\section{Discussion}

The analyses of training effects in pedal forces can indicate if a training intervention has the potential to enhance (or reduce) pedal force effectiveness. To pro- vide information on the biological error of measuring pedal forces, our study assessed reliability of pedal force variables during incremental tests to exhaustion performed on separate days by competitive cyclists and triathletes. Between-days difference ranged from 5\% to $14 \%$ for pedal force variables (small to trivial) which were greater than the variability observed in oxygen uptake.

Biological error of measurement includes the technical noise in measuring analogue signals and converting them into digital signals along with cyclists' variability in performing the movement [10]. Therefore, for the evaluation of training effects, it is important to know the size of the biological error of various measures. In our study, we collected oxygen uptake during the incremental test to present a variable that has already been shown small variability in a similar designed study using the same metabolic cart [26]. Peak normal and total force applied on the right pedal presented $6 \%$ and $5 \%$ of variation, respectively, which is similar to the results of oxygen uptake (4\%). These results may be related to the consistent high pushing forces observed by cyclists during the propulsive phase of crank revolution (from 12 o'clock to 6 o'clock crank positions) [2]. Greater variability in normal $(12 \%)$ and total force applied on the left $(11 \%)$ pedal may be due to all cyclists being right leg dominant. Further analysis of bilateral symmetry may shed light on dominance effects in pedal forces.

Compared to normal and total forces applied on the pedal, the anterior-posterior force components presented greater variability between days for right (13\%) and left (14\%) pedals. Hug et al. [13] observed that total force applied on the pedal at the top (12 o'clock crank position) and bottom dead centres (6 o'clock crank position) were more variable than the force applied at the 3 o'clock crank position. In these two areas of crank revolution (12 o'clock crank position and 6 o'clock crank position), the anteriorposterior component has greater contribution than at the 3 o'clock crank position. It is also expected that anterior-posterior force would vary because some cyclists will try to pull the pedal backward at the 6 o'clock crank position [27]. Therefore, the analysis of anterior-posterior force would be more variable then the normal and total force applied on the pedals.

The effectiveness of the force applied on the pedal was analysed by the index of effectiveness, which depends on the total and on the tangential force on the pedal and on the crank, respectively. To convert pedal force components (normal and anterior-posterior) into 
tangential crank force, the angle of the pedal must be taken into account. We would expect the greater variability on the index of effectiveness (10\% and $14 \%$ for right and left pedals) compared to the total force applied on the pedal to be related to differences in pedal angle. Variability in lower limb kinematics within a single session would be expected to depend on cycling experience [28]. However, no published study to date has presented data on variability of kinematics between days. It is possible that greater variability of the index of effectiveness may be related to variability in pedal and lower limb kinematics between days. Further research is needed to assess variability in joint kinematics acquired in separate days to measure the biological error. To compute the index of effectiveness, information on normal and anterior-posterior force components is combined with pedal angle. In our study we estimated a combined error of right and left index of effectiveness of $\sim 1.37 \%$ and $\sim 1.74 \%$ due to calibration procedures of pedal forces and potentiometers. We infer that the differences observed between days in determination of the index of effectiveness from unknown sources (e.g. cyclists/triathletes variability to perform the task) may be of $\sim 8.34 \%$ and $\sim 12.45 \%$ for right and left pedals. Bilateral symmetry in joint kinematics has been shown for non-cyclists, without reports on biological error between legs [29].

Between day variability on pedal forces did not present a trend depending on workload. For the index of effectiveness of the right pedal, moderate differences between days were observed for the $250 \mathrm{~W}$ (14\%) and trivial differences were found for $350 \mathrm{~W}$ (5\%). Within-cyclist/triathlete variability may be reduced by assessing various levels of workload and accounting for average results across different workload levels, as conducted in our study. Therefore, conclusions regarding training effects drawn by a single assessment of pedal forces may be subject to greater (or smaller) biological error leading to overestimated (or underestimated) effects of training. It is also unknown if assessing pedal force during variable workload and pedalling cadence (e.g. time trial) may change variability of pedal force variables.

One limitation of our study was not providing a session for familiarisation on the incremental test before data were collected. The automatic control of workload by the cycle ergometer software and the visual control of pedalling cadence by the cyclists/triathletes should have provided a consistent protocol with highly repetitive performance. We expected high repeatability in cycling motion due to the small variation in oxygen uptake (4\%) and peak normal force (5\%). Assessing lower limb kinematics along with pedal forces would have indicated if variability between days emerged from joint movements or from muscle force production via joint kinetics analyses.

\section{Conclusions}

Trivial differences in peak normal and anteriorposterior forces, total pedal force and index of effectiveness were observed between days. Greater reliability was found for peak normal and total force applied on the pedal, with variability increasing for anteriorposterior force and index of effectiveness. Pedal force variables were highly reliable between two to seven days of testing with similar results compared to oxygen uptake assessed during an incremental step test to exhaustion. Pedal force measures during incremental cycling tests to exhaustion can be used to assess changes in performance given the high reliability reported in our study.

\section{References}

[1] Amann M, Subudhi AW, Walker J, Eisenman P, Shultz B, Foster C. An evaluation of the predictive validity and reliability of ventilatory threshold. Med Sci Sports Exerc. 2004;36(10):1716-22.

[2] Coyle EF, Feltner ME, Kautz SA, Hamilton MT, Montain SJ, Baylor AM, Abraham LD, Petrek GW. Physiological and biomechanical factors associated with elite endurance cycling performance. Med Sci Sports Exerc. 1991;23(1):93-107.

[3] Bini RR, Diefenthaeler F. Kinetics and kinematics analysis of incremental cycling to exhaustion. Sports Biomech. 2010;9(4):223-35.

[4] Leirdal S, Ettema G. Pedaling technique and energy cost in cycling. Med Sci Sports Exerc. 2011;43(4):701-5.

[5] Mornieux G, Stapelfeldt B, Collhofer A, Belli A. Effects of pedal type and pull-up action during cycling. Int J Sports Med. 2008;29(10):817-22.

[6] Bohm H, Siebert S, Walsh M. Effects of short-term training using SmartCranks on cycle work distribution and power output during cycling. Eur J Appl Physiol. 2008;103(2):225-32.

[7] Clark N. Functional performance testing following knee ligament injury. Phys Ther Sport. 2001;2(2):91-105.

[8] Hopkins WG. Reliability from consecutive pairs of trials. In: Hopkins WG, editor. A new view of statistics. Auckland: sportsci.org: International Society for Sport Science; 2000.

[9] Soper C, Hume PA. Reliability of power output during rowing changes with ergometer type and race distance. Sport Biomech. 2004;3:237-47.

[10] Watt KKO, Hopkins WG, Snow RJ. Reliability of performance in repeated sprint cycling tests. J Sci Med Sport. 2002;5(4):354-61. 
[11] Laursen PB, Shing CM, Jenkins DG. Reproducibility of a laboratory-based $40-\mathrm{km}$ cycle time-trial on a stationary wind-trainer in highly trained cyclists. Int J Sports Med. 2003;24(7):481-5.

[12] Noordhof DA, De Koning JJ, Van Erp T, Van Keimpema B, De Ridder D, Otter R, Foster C. The between and within day variation in gross efficiency. Eur J Appl Physiol. 2010;109(6):1209-18.

[13] Hug F, Drouet JM, Champoux Y, Couturier A, Dorel S. Interindividual variability of electromyographic patterns and pedal force profiles in trained cyclists. Eur J Appl Physiol. 2008;104(4):667-78.

[14] Lucía A, Hoyos J, Pérez M, Santalla A, Chicharro JL. Inverse relationship between VO2max and economy/ efficiency in world-class cyclists. Med Sci Sports Exerc. 2002;34(12):2079-84.

[15] Weston SB, Gabbett TJ. Reproducibility of ventilation of thresholds in trained cyclists during ramp cycle exercise. J Sci Med Sport. 2001;4(3):357-66.

[16] Candotti CT, Loss JF, Melo MDO, La Torre M, Pasini M, Dutra LA, De Oliveira JLN, De Oliveira Jr LP. Comparing the lactate and EMG thresholds of recreational cyclists during incremental pedaling exercise. Can J Physiol Pharmacol. 2008;86(5):272-8

[17] Bentley DJ, Newell J, Bishop D. Incremental exercise test design and analysis: Implications for performance diagnostics in endurance athletes. Sports Med. 2007;37(7):575-86.

[18] Marfell-Jones M, Olds T, Stewart A, Carter L. International standards for anthropometric assessment. Kineanthropometry ISfAo, editor. Potchefstroom, South Africa: ISAK; 2006.

[19] Carpes FP, Diefenthaeler F, Bini RR, Stefanyshyn DJ, Faria $\mathrm{IE}$, Mota CB. Influence of leg preference on bilateral muscle activation during cycling. J Sports Sci. 2011:29(2):151-9.

[20] Candotti CT, Ribeiro J, Soares DP, de Oliveira AR, Loss JF, Guimarães ACS. Effective force and economy of triathletes and cyclists. Sports Biomech. 2007;6(1):31-43.

[21] Hull ML, Davis RR. Measurement of pedal loading in bicycling: I. Instrumentation. J Biomech. 1981;14(12):843-56.

[22] Rossato M, Bini RR, Carpes FP, Diefenthaeler F, Moro ARP. Cadence and workload effects on pedaling technique of welltrained cyclists. Int J Sports Med. 2008;29(9):746-52.

[23] Hopkins WG. Measures of reliability in sports medicine and science. Sports Med. 2000;30(1):1-15.

[24] Rhea MR. Determining the magnitude of treatment effects in strength training research through the use of the effect size. J Strength Cond Res. 2004;18(4):918-20.

[25] Cohen J. Statistical power analysis for the behavioral sciences. 2nd ed ed. Hillsdale, NJ: Lawrence Earlbaum Associates; 1988 .

[26] Crouter SE, Antczak A, Hudak JR, DellaValle DM, Haas JD. Accuracy and reliability of the ParvoMedics TrueOne 2400 and MedGraphics VO2000 metabolic systems. Eur J Appl Physiol. 2006;98(2):139-51.

[27] Diefenthaeler F, Coyle EF, Bini RR, Carpes FP, Vaz MA. Muscle activity and pedal force profile of triathletes during cycling to exhaustion. Sports Biomech. 2012;11(1):10-9.

[28] Chapman A, Vicenzino B, Blanch P, Hodges P. Do differences in muscle recruitment between novice and elite cyclists reflect different movement patterns or less skilled muscle recruitment? J Sci Med Sport. 2009;12(1):31-4.

[29] Edeline O, Polin D, Tourny-Chollet C, Weber J. Effect of workload on bilateral pedaling kinematics in non-trained cyclists. J Human Mov Stud. 2004;46(6):493-517. 